See Article page 306.

\section{Commentary: Dangerous liaisons-Paraneoplastic syndromes and thymoma}

\author{
Enrico Ruffini, MD, Paraskevas Lyberis, MD, \\ Francesco Guerrera, MD, and Pier Luigi Filosso, MD
}

The association of thymomas and autoimmune disfunctions in the form of paraneoplastic syndromes (PNSs) has long been recognized. ${ }^{1,2}$ Signs and symptoms related to PNS can be severe and life-threatening, and the prompt recognition of the thymic nature is crucial for early treatment and cure. $^{3,4}$ Although several theories have been proposed to explain the pathophysiologic link between thymoma and immunologic disorders (escape theory, ${ }^{5}$ genetic theory, ${ }^{6}$ and autoimmune regulator theory ${ }^{7}$ ), none has proved definite, and the possible mechanism may be multifactorial.

In this issue of the Journal, Zhao and colleagues ${ }^{8}$ provide a systematic review of PNSs associated with thymoma after surgical resection, particularly focusing on their prevalences, recurrences, treatment modalities, and outcomes. A remarkable methodology was used by Zhao and colleagues, ${ }^{8}$ including a primary search to identify published articles on the topic in the last 50 years and a secondary search identifying the case reports and case series referenced in the articles found in the primary search. The resulting 407 publications describing 507 patients were entered in the database and analyzed for the study. The main findings of the review are as follows: (1) A total of 123 PNSs associated with thymoma were found in the literature; of these, the most frequent are myasthenia gravis $(63 \%)$, pure red cell aplasia, lichen planus, Good syndrome, and limbic encephalitis. In $50 \%$ of the cases, 2 or more PNSs were present. (2) After thymoma resection, resolution of the PNS was observed in $76 \%$ of the patients. (3) Resolution of PNS was an independent prognostic factor, and recurrence of the initial PNS symptoms or onset of a new PNS occurred in $21 \%$ of the cases.

From the Thoracic Surgery Unit, University of Torino, Torino, Italy.

Disclosures: Authors have nothing to disclose with regard to commercial support.

Received for publication Jan 2, 2020; accepted for publication Jan 2, 2020; available ahead of print Jan 25, 2020.

Address for reprints: Enrico Ruffini, MD, Thoracic Surgery Unit, University of Torino, 14 Corso Dogliotti, 10126 Torino, Italy (E-mail: enrico.ruffini@unito.it).

J Thorac Cardiovasc Surg 2020;160:318-9

$0022-5223 / \$ 36.00$

Copyright (c) 2020 by The American Association for Thoracic Surgery

https://doi.org/10.1016/j.jtcvs.2020.01.019
Check for updates

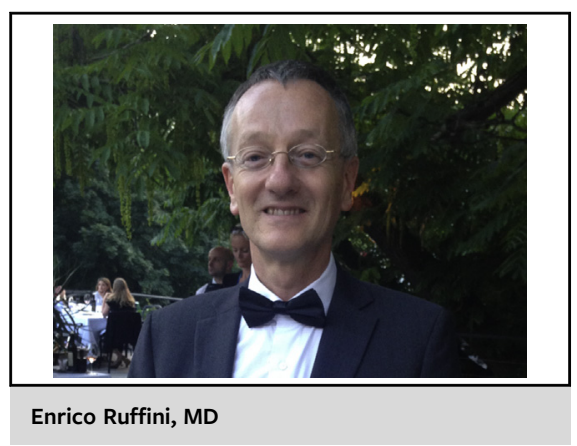

CENTRAL MESSAGE

Paraneoplastic syndromes associated with thymoma are optimally managed in a multidisciplinary setting by surgical resection of the tumor and the thymic gland and by providing lifelong follow-up.

Despite the limitations addressed by Zhao and colleagues ${ }^{8}$ in their discussion section, including the retrospective nature of the data and the high percentage of patients $(70 \%)$ with missing data on stage and histology preventing any analysis on these variables, the main strength of the article is the recognition that the spectrum of PNS is much wider than expected, that the control of the PNS is of paramount importance in the optimal management and that the surgical removal of the thymus gland and the thymoma can control the PNS in the vast majority of cases.

The major message from the article of Zhao and colleagues ${ }^{8}$ is the importance of a multidisciplinary approach to patient with thymoma and PNS. A collaborative effort that includes epidemiologists, hematologists, neurologists, and dermatologists, along with thoracic surgeons, pathologists, and medical and radiation oncologists, constitute a formidable "armada" to manage these tumors optimally. This therapeutic alliance should not terminate after surgery. Thymic tumors need to be followed up lifelong because of their propensity to recur, and this is even more valid in the presence of a PNS, for which the follow-up needs to be performed in a multidisciplinary setting, because postsurgical PNS can occur in as many $30 \%$ of these patients.

Thymic tumors and thymus pathophysiology never cease to surprise in showing us how complex and interrelated the human physiologic systems are. They seem to suggest to us that only with an integrated, coordinated, collaborative 
effort will we be able to advance our science in the knowledge of thymus gland and the management of thymic tumors, for the benefit of our patients.

\section{References}

1. Hoffacker V, Schultz A, Tiesinga JJ, Gold R, Schalke B, Nix W, et al. Thymomas alter the T-cell subset composition in the blood: a potential mechanism for thymoma-associated autoimmune disease. Blood. 2000;96:3872-9.

2. Evoli A, Lancaster E. Paraneoplastic disorders in thymoma patients. J Thorac Oncol. 2014;9(9 Suppl 2):S143-7.

3. Ruffini E, Filosso PL, Mossetti C, Bruna MC, Novero D, Lista P, et al. Thymoma: inter-relationships among World Health Organization histology, Masaoka staging and myasthenia gravis and their independent prognostic significance: a singlecentre experience. Eur J Cardiothorac Surg. 2011;40:146-53.
4. Padda SK, Yao X, Antonicelli A, Riess JW, Shang Y, Shrager JB, et al. Paraneoplastic syndromes and thymic malignancies: an examination of the International Thymic Malignancy Interest Group Retrospective Database. J Thorac Oncol. 2018;13:436-46.

5. Kyewski BA. Thymic dendritic cells present blood-borne antigens to medullary thymocytes in vivo: a possible role in the generation of the T-cell repertoire. Haematol Blood Transfus. 1985;29:486-91.

6. Okumura M, Fujii Y, Shiono H, Inoue M, Minami M, Utsumi T, et al. Immunological function of thymoma and pathogenesis of paraneoplastic myasthenia gravis. Gen Thorac Cardiovasc Surg. 2008;56:143-50.

7. Puissant B. Thymus function and autoimmunity [in French]. Rev Med Interne 2004;25:562-72.

8. Zhao J, Bhatnagar V, Ding L, Atay SM, David EA, McFadden PM, et al. A systematic review of paraneoplastic syndromes associated with thymoma: treatment modalities, recurrence, and outcomes in resected cases. J Thorac Cardiovasc Surg. 2020;160:306-14.e14. 